\title{
El encomendero Polo de Ondegardo y los mitimaes del valle de Cochabamba: los interrogatorios contra los indios de Paria y Tapacarí
}

\author{
Juan J. R. Villarías Robles \\ Escuela de Estudios Hispano-Americanos, CSIC. Sevilla \\ Ítala de Mamán \\ Archivo Histórico Municipal de Cochabamba. Bolivia
}

Los autores ofrecen una nueva transcripción de dos interrogatorios judiciales relacionados con Polo de Ondegardo (ca. 1520-1575) y la situación en el valle de Cochabamba (Bolivia) en el siglo XVI. Los dos documentos ayudan a entender el concepto que tenía Polo de Ondegardo sobre los mitimaes en el imperio inca. También ilustran sobre el importante papel económico que podía llegar a tener esta categoría social en el orden incaico. Los mitimaes no perdían por ello necesariamente la vinculación con sus grupos étnicos de origen, contrariamente a la idea más extendida sobre los llamados "mitimaes del Inca" que se encuentra en la bibliografía.

\section{Introducción}

Desde hace unos veinte años, el estudio de la documentación existente en el Archivo Histórico de Cochabamba (Bolivia) está permitiendo conocer detalles de la economía política inca en el valle del mismo nombre que son de una importancia comparable a los que se tienen de otras zonas no nucleares del imperio inca, como la provincia de Chucuito, en la cuenca del lago Titicaca, ${ }^{1}$ la cuenca de Huánuco ${ }^{2}$ o el valle de Chincha. ${ }^{3}$ Presentamos aquí una nueva transcripción de dos interrogatorios judiciales relacionados con el jurista y funcionario colonial español Polo de On-

1 Díez de San Miguel, Garci: Visita hecha a la provincia de Chucuito [...] [1567]. Edición de Waldemar Espinoza Soriano. Lima, 1964.

2 Ortiz de Zúñiga, Iñigo: Visita de la provincia de León de Huánuco en 1562 [1549, 1562]. Edición de John V. Murra. Huánuco, Perú, 1967-1972.

3 Castro, Cristóbal de y Ortega Morejón, Diego: Relación y declaración del modo que este valle de Chincha y sus comarcanos se governavan antes que hobiese Ingas y después que los hobo hasta que los cristianos entraron en esta tierra [1558]. Colección de Documentos Inéditos para la Historia de España, vol. 50, págs. 206-220. Madrid, 1867. Rostworowski de Díez Canseco, María: "Mercaderes del valle de Chincha en la época prehispánica: un documento y unos comentarios". Revista española de antropología americana, vol. 5, Madrid, 1970, págs. 135-178. 
degardo ( $c a$. 1520-1575), quien fue encomendero en el valle. Los dos son relevantes para la comprensión de la categoría social de los mitimaes en el orden incaico, así como informativos del pensamiento de Polo de Ondegardo acerca de ella. ${ }^{4}$ La transcripción deriva de un nuevo estudio de los textos originales, así como del contexto documental e histórico al que pertenecen. Nuestro trabajo viene a sumarse a otros recientes sobre las condiciones en el valle de Cochabamba en el periodo inca y las primeras décadas del régimen colonial. ${ }^{5}$

Las fuentes españolas sobre este imperio (v. g., Pedro de Cieza de León, ${ }^{6}$ fray Domingo de Santo Tomás, ${ }^{7}$ Diego Fernández, ${ }^{8}$ el propio Polo de Ondegardo $0^{9}$ llamaban con este nombre, "mitimaes", o "mitimas" — del

4 Esta nueva versión de los dos interrogatorios forma parte de la compilación crítica de las obras completas de Polo de Ondegardo y los documentos sobre su vida que coordina Fermín del Pino Díaz. Agradecemos el que nos haya permitido publicar aquí nuestro trabajo antes que en esa compilación. Agradecemos también sus comentarios a la valoración que hacemos de los dos documentos; valoración enriquecida asimismo por las sugerencias de Catherine Julien, Berta Ares Queija y Alfredo Moreno Cebrián. Uno de nosotros, Juan J. R. Villarías Robles, pudo llevar a cabo su parte de la investigación gracias a una beca de viaje de la Universidad de Chicago y a fondos asignados al proyecto PB89-0051 patrocinado por el Ministerio de Educación y Ciencia de España, titulado "Discursos etnográficos y contextos histórico-sociales", dirigido por Pino Díaz, del que este trabajo es uno de sus resultados.

5 Universidad Mayor de San Simón (U.M.S.S.), Cochabamba, Departamento de Arqueología: Repartimiento de tierras por el Inca Huayna Cápac. Edición de Adolfo de Morales y Geraldine Byrne de Caballero. Cochabamba, 1977. Wachtel, Nathan: "The Mitimas of the Cochabamba Valley". The Inca and Aztec States, 1400-1800: Anthropology and History. Edición de G. A. Collier, R. I. Rosaldo y J. D. Wirth. Nueva York, 1982, págs. 199-235. Gordillo, José María y Mercedes del Río (eds.): La visita de Tiquipaya. Cochabamba, 1993. Villarías Robles, Juan J. R.: "La importancia de la categoría social de los 'mitimaes' en la configuración económico-política del imperio inca; nuevos datos procedentes del Archivo Histórico de Cochabamba (Bolivia)". Actas del IV Encuentro de Americanistas Españoles (Salamanca, 1994). Salamanca, 1995, págs. 1601-1633. Villarías Robles, Juan J. R. y Pereira Herrera, David: "El emplazamiento de Canata y la fundación colonial de la villa de Oropesa: una contribución a la geografía histórica del valle de Cochabamba (Bolivia) en los siglos XV y XVI”. Revista Andina, año 13, n. ${ }^{\circ}$, Cusco, 1995, págs. 199-236.

6 La crónica del Perú: parte primera [1553]. Edición de Carmelo Sáenz de Santa María. Madrid, 1984. Véanse los capítulos 53, 57, 74, 87, 92, 93 y 99.

7 Lexicon o vocabulario de la lengua general del Perú [1560]. Edición facsimilar de R. Porras Barrenechea. Lima, 1951.

8 Primera y segunda parte de la historia del Perú [1571]. Edición de Juan Pérez de Tudela Bueso. Madrid, 1963. Véase la parte II, libro 3, capítulo 11.

9 "Informe [...] al licenciado Briviesca de Muñatones sobre la perpetuidad de las encomiendas en el Perú" [1561]. Edición de Carlos A. Romero. Revista Histórica, órgano del Instituto Histórico del Perú, vol. 13, Lima, 1940, págs. 125-196. "Relación de los fundamentos acerca del notable daño que resulta de no guardar a los indios sus fueros y de la orden que los indios tenían en dividir los tributos entre sî" [1571]. [También conocida como "Relación acerca del linaje de los incas y cómo conquistaron, y acerca del notable daño que resulta de no guardar a los indios sus fueros"]. Colección de Documentos Inéditos del Archivo de Indias, vol. 17, págs. 5-177. Madrid, 1872. 
vocablo quechua mitmaq-, a todos los grupos de familias que residían en un territorio alejado de su lugar de origen, al que habían sido desplazados por razones de tipo político, militar o económico; o por varias de estas causas a la vez.

$\mathrm{Su}$ papel en la vertebración del poder incaico ha sido objeto de discrepancias entre los estudiosos, como lo fue entre los autores de esas fuentes. La documentación publicada en las últimas décadas sobre otras zonas, como la mencionada provincia de Chucuito, sugiere que las colonias de mitimaes — al menos en estas regiones — eran anteriores a la formación del imperio inca y existían en función del aprovechamiento local de la peculiar ecología andina, con sus múltiples recursos complementarios dispuestos verticalmente y a grandes distancias del hábitat del grupo étnico que decidiera explotarlos. ${ }^{10}$ Polo de Ondegardo trató de estas colonias - y de los problemas que le ocasionaron a la división administrativa española- en sus informes citados de 1561 y 1571 , especialmente en el primero. Contó el caso de su intercesión ante el virrey Marqués de Cañete (1556-1560) para que los mitimaes que tenían en la costa los carangas, en el altiplano boliviano, y "los de Chucuito" fueran devueltos administrativamente a sus naciones de origen y, por tanto, a la dependencia de sus caciques. Esos mitimaes habían sido encomendados a vecinos de la ciudad de Arequipa al fundarse ésta en 1540, lo que había roto su vinculación con esas naciones. Nuestro autor razonaba que las colonias de mitimaes habían contribuido significativamente desde tiempo inmemorial al sostenimiento material de sus pueblos, y que ésta era una de las peculiaridades de un orden económico-político que convenía salvaguardar en todo lo posible en aras del enraizamiento del régimen colonial. Polo añadió que había logrado su propósito: los mitimaes fueron devueltos a los carangas o a Chucuito, y los vecinos de Arequipa afectados fueron compensados con encomiendas de otros indios que no planteaban el mismo problema.

Los incas habían adaptado estos "archipiélagos ecológicos" a su dominio, como habían hecho con la organización económica de otras zonas; sin embargo, crearon también nuevas colonias de mitimaes. No hay duda de que esta política perseguía la protección de las fronteras del imperio y la consolidación del poder incaico en territorios que habían sido incorporados a él con dificultad. Dado que el número de estas colonias parece

10 Murra, John V: "Un reino aymara en 1567" [1968]. Formaciones económicas y políticas del mundo andino. Lima, 1975, págs. 193-223. "El control vertical de un máximo de pisos ecológicos en la economía de las sociedades andinas” [1972]. Ibídem, págs. 59-115. 
que fue considerable, cabe pensar, con J. Rowe, ${ }^{11}$ que esta política de los incas debió atenuar mucho el poder disgregador que tenía para el imperio la diversidad étnica y organizativa de su población. Pero muchas de estas colonias, vistas de otro modo, en la medida en que fueron creadas a la fuerza no podían ser sino indicadores de inestabilidad del dominio incaico, como ya apuntaba en el siglo XVI Diego Fernández y ha argumentado, entre los investigadores contemporáneos, W. Espinoza Soriano. ${ }^{12}$

La documentación conservada en el Archivo Histórico de Cochabamba (en adelante, AHMCo) sugiere una realidad aparte, que complica aún más el panorama social, político y económico de este imperio: la creación de colonias de mitimaes podía perseguir también, al menos en ciertas zonas, los objetivos de la economía política inca —esto es, los volúmenes de producción suficientes para sostener material e ideológicamente el poder incaico-, lo que exigía contraprestaciones a las poblaciones que debían ser movilizadas para cumplir con esos objetivos. Estas contraprestaciones podían redundar en la afirmación identitaria de tales poblaciones frente al poder central, aunque sin llegar necesariamente a cuestionarlo.

La alteración de los componentes en esta ecuación tendría el mismo efecto. En aras de la legitimidad de su hegemonía, los incas podrían ofrecer tierras a muchas de las naciones incorporadas al imperio en lugares ecológicamente diferentes - cuyo aprovechamiento necesitaban- y, a cambio, estas naciones tendrían que trabajar en otras tierras, en los mismos nichos ecológicos, para el sostenimiento del dominio incaico; lo que reforzaba su identidad étnica.

El primer interrogatorio que presentamos, de 1563, contra los indios de Paria, fue publicado por Nathan Wachtel en un apéndice a su estudio sobre los mitimaes del valle de Cochabamba, junto con las respuestas a algunas de las preguntas del primero de los 13 testigos. El segundo interrogatorio, de 1568, contra los indios de Tapacarí, es mucho menos conocido, pero está estrechamente relacionado con el primero; lo publicó en 1949 el erudito boliviano José M. Urquidi, en un libro que escribió sobre la historia temprana de la ciudad de Cochabamba, fundada en $1571 .{ }^{13}$

11 "Inca Culture at the Time of the Spanish Conquest". Handbook of South American Indians, vol. 2, págs. 183-330. Edición de Julian B. Steward. Nueva York, 1946, p. 270. "Inca Policies and Institutions Relating to the Cultural Unification of the Empire". The Inca and Aztec States, 1400-1800..., págs. 96-107.

12 Por ejemplo, en "Los mitmas huayacuntus en Cajabamba y Antamarca, siglos XV y XVI". Historia y Cultura, vol. 4, Lima, 1970, págs. 77-96.

13 El origen de la noble villa de Oropesa: la fundación de Cochabamba en 1571 por Gerónimo Osorio [1949]. Segunda edición. Cochabamba, 1971. 
Los dos interrogatorios forman parte de los expedientes judiciales de sendos pleitos conservados en el AHMCo; pleitos que, a su vez, son una pequeña muestra de una serie de litigios que tuvieron lugar entre 1555 y 1590 por las fértiles tierras del valle, en los que participaron diversos agentes movidos por los dos tipos de demanda que generaba entonces la explotación minera de Potosí: (1) la de productos agrícolas y ganaderos necesarios para alimentar y vestir a la creciente población del centro minero, y (2) la de trabajo en las minas y otras formas de tributo indígena, que debía provenir de los grupos étnicos más próximos al lugar. Estos grupos, como forma de contraprestación ante esa imposición tributaria, pidieron a las autoridades españolas la devolución de las tierras en el valle de Cochabamba que, según ellos, el Inca Huayna Cápac les había asignado allí a cambio de trabajar en otras, también en el valle, para el Estado incaico: bien periódicamente, como mitayos, o bien permanentemente, como mitimaes.

Su reclamación chocaba con los intereses de quienes cultivaban esas tierras desde la destrucción del dominio inca: los hacendados españoles, los residentes indígenas y los encomenderos de éstos. Paradójicamente, muchos de esos residentes indígenas eran descendientes de mitayos y mitimaes del Inca, quienes habían llegado al valle procedentes de los mismos grupos étnicos de la alta Bolivia que ahora demandaban esas tierras. Los mismos indígenas debían hacer frente, por otro lado, a las demandas de los hacendados españoles, cada vez más numerosos — notablemente tras la fundación de Cochabamba en 1571- y que deseaban tierras con el fin de orientar su producción al mercado de Potosí.

La publicación, por la Universidad de San Simón, de parte del expediente de uno de los litigios resultantes de esos conflictos, en 1575-1578 - entre los indígenas encomendados a Polo de Ondegardo y Rodrigo de Orellana, de una parte, y los carangas y otras naciones del Altiplano, de otra- ${ }^{14}$ permitió ilustrar lo que había sido la acción de los incas en la mitad occidental del valle de Cochabamba: aquella en la que Huayna Cápac había asignado tierras a esas naciones del Altiplano. El expediente contiene una copia notarial de un texto conocido como "Repartimiento de tierras por el Inca Huayna Cápac", que es un fragmento de una visita hecha al valle por Juan González entre 1556 y 1560 a instancia de los caciques de Paria.

14 El expediente está en el legajo EC-17 1570-1704, antes llamado "AR 1570”, ff. 404-462v y lleva el engañoso título "Proceso de los indios carangas sobre las tierras de Colcapirhua" en el índice parcial de R. Schramm de los fondos del AHMCo: "Archivo Histórico de Cochabamba: Índice de documentos sobre indios y tierras (siglos XVI, XVII y XVIII)”. Revista Andina, año VIII, n. ${ }^{\circ} 1$, Cusco, 1990, págs. 187-236. 
Los dos interrogatorios que aquí presentamos —el primero de los cuales corresponde a ese litigio iniciado por los caciques de Paria— hacen más clara aún la naturaleza del conflicto que separaba a los dos bandos indígenas.

\section{Interrogatorio contra los indios de Paria}

El 2 de abril de 1563, en la localidad de Canata, en el valle de Cochabamba, dos "caciques principales" del valle, Hernando Cuyo y Diego Tanquire - el primero encomendado a Rodrigo de Orellana y el segundo a Polo de Ondegardo-, se presentaron ante "el justicia del partido de Cochabamba" de entonces, Martín de la Rocha, y le hicieron entrega de una "carta receptoria" de la Audiencia de Charcas y un interrogatorio de 19 preguntas. La "carta receptoria" tenía fecha de 23 de enero de ese año y en ella la Audiencia explicaba que intervenía en un pleito entre los indios de Paria, en la sierra boliviana, y los del valle de Cochabamba sobre ciertas tierras que había en éste, y que estos últimos habían solicitado la carta tras plantear el problema de que las personas que podían testificar en su favor no podían desplazarse hasta La Plata (hoy Sucre), sede de la Audiencia, para comparecer ante ella. El tribunal había accedido a esta petición y por la carta ordenaba a las autoridades ante quienes se presentase que, en el plazo de seis meses, practicaran una "probanza" mediante testigos que hiciera valer la argumentación de los caciques de Cochabamba. Las declaraciones de esos testigos habían de hacerse contestando cada uno a las preguntas del interrogatorio que los caciques presentaran, aunque el documento debía ir firmado por el secretario de la Audiencia, Tristán Sánchez.

El interrogatorio que presentaron Cuyo y Tanquire ante Martín de la Rocha puede ser consultado en el AHMCo junto con la carta de la Audiencia, las respuestas de los 13 testigos presentados y otros autos de la probanza que Martín de la Rocha hizo en Canata. El conjunto forma un expediente que R. Schramm ha titulado "Probanzas en el pleito entre los indios de Cochabamba y Paria sobre las tierras del valle". ${ }^{15}$

15 El expediente comprende las fojas 349 a 396v del volumen EC-16, antes llamado "AR 1540 ". El interrogatorio comprende las fojas 351 a 354 . Como para el segundo que presentamos, hemos seguido las reglas de transcripción recomendadas por Rivera Serna, Raúl: "Principios sobre archivología y paleografía". Estudios UMSS, Publicación semestral del Centro de Formación e Investigación Interdisciplinaria de la Universidad Mayor de San Simón de Cochabamba, año II, n. ${ }^{\circ} 3$, Cochabamba, 1989, págs. 86-107. Estas reglas de transcripción son las aprobadas por la Primera Reunión Interamericana de Archivos, celebrada en Washington en octubre de 1961. 
El interrogatorio no tiene fecha, pero ésta cabe situarla entre la de la carta de la Audiencia, 23 de enero de 1563, y la del día en que Cuyo y Tanquire se lo entregaron a Martín de la Rocha, el 2 de abril del mismo año.

Como había ordenado la Audiencia, el texto lleva la firma de Tristán Sánchez. No hay más firmas en él, pero al final, antes de la firma de Sánchez, se leen los nombres de "El liçençiado Polo", "El liçençiado Pedro de Herrera" y "Françisco Muñoz", que deben ser los de los autores —por orden de protagonismo - del texto original, que Sánchez debió copiar y firmar para que Cuyo y Tanquire lo llevaran, junto con la carta, al valle de Cochabamba.

Como ya sabemos, Polo tenía entonces una de las encomiendas del valle, de las tres constituidas tras la derrota de la sublevación de Gonzalo Pizarro, en 1548. El tercer autor, Francisco Muñoz, era el procurador de Cuyo y Tanquire ante la Audiencia, según dice la carta. En cuanto a Pedro de Herrera, su papel en el caso se desconoce, pues su nombre aparece sólo en el interrogatorio. En 1561, un Pedro de Herrera había sido "teniente de corregidor y justicia mayor en el asiento de minas de Berenguela y los valles de Cochabamba y Cliza", según consta en dos expedientes de ese año que también se guardan en el AHMCo. ${ }^{16}$ Otro expediente, éste guardado en el Archivo General de Indias, en Sevilla, ${ }^{17}$ menciona a un Pedro de Herrera como apoderado en 1562-1565 de Hernando de Silva ante la Audiencia de Lima y los oficiales de la Hacienda Real de Potosí. Silva había tenido hasta entonces otra de las encomiendas del valle de Cochabamba - la de los indios de Sipe Sipe - y estaba a punto de perderla en beneficio de la Corona por haber regresado a España de manera presuntamente irregular. Es muy posible que el Pedro de Herrera mencionado en los tres expedientes sea la misma persona, aunque esto no nos dice mucho de su papel en el pleito entre los indios encomendados a Polo y Rodrigo de Orellana, de una parte, y los indios de Paria, de otra. Tal vez fue el apoderado de Rodrigo de Orellana. El texto firmado por él, Muñoz y Polo, junto con el resto de los autos del proceso seguido en la Audiencia de Charcas, debieron quedar en poder de Tristán Sánchez en La Plata. El expediente generado por estas actuaciones aún no se ha encontrado.

16 EC-2, ff. 52-61v [1561], "Títulos de las tierras de Francisco Vázquez en Guayruro y Condepampa". EC-16, ff. 244-252v [1561], "Averiguación sobre las tierras de Guayruro y Condepampa que pide Francisco Carrillo".

17 Justicia 656, n. ${ }^{\circ} 1$, ramo 3, "El fiscal con Hernando de Silva [...] sobre el pago de los tributos del pueblo de Zipe Zipe que tenía en encomienda" [1564], ff. 2-8v. 
Por las preguntas del interrogatorio descubrimos que las tierras en litigio se llamaban Poto Poto, Illaurco, Colchacollo, Anocaraire y Villaoma, dándonos a entender que los "indios de Paria" que las reclamaban eran de las etnias sora y uru. Las tierras son las mismas que aparecen mencionadas en el litigio de los carangas y sus aliados, doce años posterior; eran grandes parcelas ("chácaras") que estaban ubicadas en la mitad occidental del valle y habían sido subdivididas en lotes llamados "suyos", "urcos" o "suertes". Los carangas y sus aliados pedirían ocho de estos lotes. Suponemos que los de Paria pidieron otros, en las mismas "chácaras". Según el texto del repartimiento de tierras de Huayna Cápac, fue en ellas donde el Inca les asignó el cultivo de cinco lotes: dos en Illaurco, dos en Colchacollo y uno en Villaoma. ${ }^{18}$

También descubrimos por el interrogatorio que la posición en el pleito de los indios encomendados a Polo y Rodrigo de Orellana era esencialmente la misma que la que opondrían más tarde a los carangas, a saber: que los indios de fuera del valle no tenían ningún derecho a tierras en él, porque estas tierras habían pertenecido al Inca y, antes, a los naturales del valle. A muchos de estos naturales el Inca los había enviado a otros lugares; por ejemplo, a Totora, "que está junto a los Andes". Quienes las poseían ahora eran los mitimaes que el Inca había traído de fuera del valle para trabajar en ellas, en beneficio del Estado incaico. Se trataba de familias que no tenían ya nada que ver con sus etnias de origen, aunque entre éstas estuvieran los soras y los urus de Paria. ${ }^{19}$ Muchos de los indios encomendados a Polo y Rodrigo de Orellana, si no todos — según sabemos por el expediente del pleito de los carangas-, eran, en efecto, mitimaes puestos por el Inca, o descendientes de ellos. Había también descendientes de mitayos, como sabemos por el mismo expediente; pero este interrogatorio no los menciona, como tampoco hará el interrogatorio contra Tapacarí.

Los autores alegaron asimismo, en favor de los habitantes del valle, un segundo argumento: que no es bueno que los mitimaes y las tierras que cultivan sean devueltos a sus naciones de origen, ya que la política general española en todo el Virreinato es que no lo sean. ${ }^{20}$ Este segundo argumento sorprende, por dos motivos. En primer lugar, porque parece contradecir el argumento anterior: se da a entender ahora que hay mitimaes en el valle que continúan sintiéndose vinculados a sus etnias de origen, y que estas

\footnotetext{
18 AHMCo, EC-17 1570-1704, Proceso de los indios carangas..., ff. 419-427.

19 Véase el contenido de las preguntas III, IIII, V, XV.

20 Véase las preguntas XIIII y XV.
} 
poblaciones de fuera del valle pueden tener algún derecho a tales mitimaes o a sus tierras, a pesar de la distancia que pueda haber entre unos y otros. En las preguntas V y VI llega a afirmarse que la causa de la desvinculación de los mitimaes con sus etnias de origen había sido la intervención española, no la política inca de establecer colonias con tales mitimaes.

En segundo lugar, el argumento contrasta notablemente con lo razonado por Polo de Ondegardo sobre los mitimaes carangas y de Chucuito que cayeron bajo la jurisdicción de Arequipa. El interrogatorio alude a esos mitimaes en la pregunta XIV, pero, sorprendentemente, omite la intercesión de Polo en el caso, que permitió resolverlo de manera favorable tanto para el orden indígena como para el régimen colonial: omisión que obliga a tomar con reservas el alegato de que era política general española en el Virreinato el mero criterio de la proximidad territorial a ciudades españolas para repartir mitimaes entre encomenderos. Si a ello se añadiera la diferencia de razonamientos presentados en uno y otro texto, se podría pensar, como ha hecho Wachtel, ${ }^{21}$ que Polo simplemente estaría defendiendo sus propios intereses como encomendero en el caso de los mitimaes de Cochabamba, sin importarle mucho si esto se contradecía con sus ideas sobre el orden incaico expuestas en trabajos como el de 1561. En coherencia con esas ideas, Polo debía estar a favor, no en contra, de devolverles a los indios de Paria sus mitimaes y las tierras reclamadas en el valle, como se había hecho con los mitimaes de los carangas y de Chucuito en la costa.

Sin embargo, conviene tener presente que en esos trabajos Polo distingue con claridad al menos dos clases de mitimaes: aquellos que, si bien "puestos por el Inca", estaban a las órdenes de los caciques de sus naciones, y los que, constituidos también por el Inca, estaban sin embargo a sus órdenes o a las de sus gobernadores. Cieza de León había percibido la misma diferencia unos diez años antes. ${ }^{22}$ La primera clase tenía el sentido que manifiesta el siguiente pasaje:

"El Inca tuvo tan buena orden que [a] cada provincia dio medios para que tuviese lo necesario y cogiese sustentación para pasar la vida, y así, cuando están poblados [los indios] en tierra fría, [les] repartió tierra en la caliente, aunque fuese lejos, e hizo poner en ella [en la tierra caliente] indios de cada provincia para que se enviasen

21 “The Mitimas...”, págs. 200-201.

22 La crónica del Perú... Compárese la descripción que hace este autor de las colonias de mitimaes en lugares como Tumbes (cap. 53), Guancabamba, en la sierra norte peruana (cap. 57), o el valle de Chincha (cap. 74), con la que hace de las del Collao (cap. 99). 
y beneficiasen las semillas que se dan y cogen [en ella], y ordenó que la comunidad enviase por ello en sus ganados; sin la cual orden no se pueden cómodamente sustentar". ${ }^{23}$

Los mitimaes de los carangas y de Chucuito en la costa eran de esta primera clase, y de hecho Polo los señala como ejemplo unas líneas después del pasaje citado.

Por el contrario, la segunda clase de mitimaes era de los que "salían de la sujeción de los caciques y de su naturaleza" ${ }^{24}$ y eran un instrumento de política imperial, como los que el Inca "puso de unas partes en otras [...] para seguridad de la gente y que, como recién conquistada, no se alterase". ${ }^{25}$ Los mitimaes de Cochabamba serían de esta segunda clase, a juicio de Polo, pues el Inca los había puesto allí para que del producto de su trabajo en las tierras en litigio "comiese él y su gente de guerra, llevándoselo a la ciudad del Cuzco en sus ganados", según se alega en la pregunta III. Los mitimaes de Totora, mencionados en la pregunta XV, serían del mismo tipo. Como también lo serían los huayacuntus estudiados por W. Espinoza Soriano.

$\mathrm{Al}$ servir a los intereses más directos del Estado incaico, esta segunda clase de mitimaes le planteaban al régimen colonial un problema distinto que los de la primera clase. Los españoles habían derrocado a los incas y podían disponer libremente de sus recursos, tanto materiales (por ejemplo, tierras) como humanos (por ejemplo, mitimaes); pero en la medida en que el nuevo régimen dependía de la integridad del orden económico-político de los cacicazgos que le servían de base, la protección de esa integridad era una cuestión vital para ese régimen. Este es el razonamiento que cabe inferir de lo alegado en las preguntas V, VI y XV. Paradójicamente, el interrogatorio sugiere, como hemos visto, que ni siquiera los mitimaes de la segunda clase "salían de la sujeción de los caciques y de su naturaleza", contradiciendo así a Polo y a lo que es un lugar común en la bibliografía moderna sobre el imperio inca.

Queda aún por explicar la omisión en la pregunta XIV de la resolución del problema planteado por los mitimaes carangas y de Chucuito en la costa. Tal vez no fuera necesario mencionar el caso, al dejar constancia Polo, en su informe de 1561, de la diferencia entre las dos clases de mitimaes. No olvidemos, por otra parte, que el interrogatorio llevaba también originalmente las firmas de Pedro de Herrera y Francisco Muñoz y que por ello debe ser

\footnotetext{
23 Polo de Ondegardo: "Informe [...] al licenciado Briviesca de Muñatones...", pág. 177.

24 "Relación de los fundamentos acerca del notable daño que resulta...", págs. 43-44.

25 "Informe [...] al licenciado Briviesca de Muñatones...", pág. 134.
} 
entendido, antes que nada, como un documento que recoge el pensamiento de los tres acerca de las condiciones económicas, sociales y políticas en el valle de Cochabamba y territorios aledaños antes y después de la caída del imperio inca: pensamiento que naturalmente algo tendría que ver con el hecho de que al menos Polo y Francisco Muñoz eran parte interesada en la interpretación que aceptara la Audiencia de esas condiciones.

Wachtel atribuyó el interrogatorio exclusivamente a Polo, sin aportar otros documentos que lo demostraran, y lo fechó por error en 1560. También lo consideró parte del expediente del pleito de los carangas; pero, como ya hemos señalado, se trata de dos litigios distintos, aunque revelan un mismo tipo de conflicto. Al transcribir el documento, Wachtel decidió no poner ningún acento en ninguna palabra, ni ningún signo de puntuación en el texto, salvo puntos para separar las preguntas. Explicables tal vez desde un estrecho punto de vista histórico, estas decisiones dificultan innecesariamente la comprensión del documento. Wachtel, en cualquier caso, no hizo referencia a ninguna regla de transcripción que las justificara. Más lamentable aún es que su versión adolece de algunos errores de lectura, como leer "mitimaes chilques y chiles y collas de Asángaro" por "mitimaes chilques y chiles y collas y de Asángaro" en la pregunta VII; o leer "indios caracotas chichas y charcas y amparayes" por "indios caracaras y chichas y charcas yamparayes" en la pregunta IX. Estos errores son importantes en la medida en que el investigador francés recurrió precisamente al interrogatorio para intentar discernir el origen étnico de los mitimaes del valle. ${ }^{26}$ Con nuestra versión creemos haber subsanado estas deficiencias, que no hacen justicia al valor del documento.

\section{Interrogatorio contra los indios de Tapacarí}

Wachtel no mencionó el segundo interrogatorio que presentamos aquí, a pesar de citar la obra de J. M. Urquidi en la que va inserto. ${ }^{27}$ Esta transcripción del erudito boliviano, como la de Wachtel del interrogatorio contra Paria, tiene errores. La pregunta 4, por ejemplo, aparece transcrita así:

"Item. Si saven, etc. Que con todo lo que de dichas tierras se cogía acudían al Inca y a sus mayordomos y le llevaban y ponían en los depósitos de Paria y Tapacarí, questavan fechos para el dicho efeto, de donde los ganados del Inca lo ponían en los depósitos del (ilegible) y de ahí llevavan otros hasta el Cuzco ...”.

26 "The mitimas...", pág. 202.

27 El origen de la noble villa de Oropesa..., págs. 124-126. 
En el original, sin embargo, se lee sin dificultad lo siguiente (hecha la salvedad de las diferencias por uso de distintas normas de transcripción):

“... acudían al Inga y a sus mayordomos y lo llevaban y ponían en los depósitos de Paria y Tapacarí, questavan fechos para el dicho efeto, de donde los ganados del Inga lo ponían en los depósitos de Luricachi, y de allí lo llevaban otros hasta el Cuzco ..."

En la pregunta 5, por poner otro ejemplo, Urquidi transcribió:

"Item. Si saben, etc. Que para efeto que no huviese descuidado en lo suso dicho y lo sembrasen y cogiesen apto (?) y para que en lo que se cogía (hu)oviese recaudo y no se tomase ni notase cosa alguna de ello, tenía el Inca ..."

De nuevo el contenido real de la pregunta es otro:

"... que para efeto que no huviese descuido en lo susodicho y lo senbrasen y cogiesen a tiempo, y para que en lo que se cogía oviese recaudo y no se tomase ni hurtase cosa alguna dello, tenía el Inga ..."

Las circunstancias históricas de este segundo interrogatorio son casi las mismas que las del primero, aunque es cinco años posterior a él. Son ahora los indios de Tapacarí, asentados en la cordillera que cierra el valle de Cochabamba por el oeste, quienes reclaman tierras en el valle a los indios que residen en él encomendados a Polo y Rodrigo de Orellana. Las tierras en litigio son otra vez las de Colchacollo, Poto Poto e Illaurco, pero no las de Anocaraire y Villaoma del pleito anterior.

El 25 de mayo de 1568, de nuevo en Canata, Gerónimo Cuyo, Diego Tanquire y un cuarto cacique que aparece ahora por primera vez, Hernando Quilo, presumiblemente encomendado a Rodrigo de Orellana, hicieron entrega del interrogatorio a Andrés de Ribera, teniente de corregidor y justicia mayor entonces en el partido de Cochabamba. Al interrogatorio adjuntaron la "carta receptoria" correspondiente de la Audiencia de Charcas ordenando una nueva probanza mediante testigos que apoyara su argumentación contra los indios de Tapacarí. La carta llevaba fecha de 10 de abril de 1568, daba 50 días de plazo para la probanza y, como la anterior, mandaba que las preguntas se hicieran con arreglo a un interrogatorio que firmara Tristán Sánchez. A diferencia de la de 1563, esta segunda carta mencionaba a Polo como parte litigante junto a "los caciques principales" del valle. 
La carta, el interrogatorio presentado y las respuestas de los 7 testigos llamados a declarar forman parte de otro expediente que se conserva en el AHMCo. ${ }^{28}$

Firmado en efecto por Tristán Sánchez, el interrogatorio abunda en los argumentos del primero, rechazándose ahora enfáticamente que los mitimaes mantuvieran ningún tipo de vinculación con "caçiques ni otra persona donde heran naturales" (pregunta 7). El propio documento nos informa de que esto no era verdad en el caso de los de Tapacarí, quienes hasta tenían su propio cacique en el valle; pero se afirma que era la única excepción, porque la comunidad de Tapacarí estaba a tan sólo a siete leguas de distancia del valle (pregunta 11).

También ofrece este segundo interrogatorio detalles adicionales sobre la composición étnica de los mitimaes y la organización económica en el valle antes y después de la conquista española, si bien algunos testigos matizaron o corrigieron lo afirmado en algunas preguntas. El texto original llevaba las firmas de Polo, "don Hernando" (presumiblemente Hernando Quilo) y "don Gerónimo" (Gerónimo Cuyo), por este orden.

Lamentablemente, la argumentación de los indios de Tapacarí tampoco la conocemos en detalle. El expediente de este segundo proceso abierto por la Audiencia de Charcas tampoco se ha encontrado.

28 Schramm lo tituló "Probanzas en el pleito entre los indios de Cochabamba (y el licenciado Polo) y de Tapacarí"; comprende las fojas 397 a 421 del citado volumen EC-16. El interrogatorio comprende las fojas 400 a $401 \mathrm{v}$. 


\section{Apéndice}

\section{INTERROGATORIO CONTRA LOS INDIOS DE PARIA}

[351] +Por las preguntas siguientes sean preguntados los testigos que fueren presentados por parte de don Hernando Cuyo e don Diego Tanquire e don Gerónimo Cuyo, caçiques del valle de Cochabamba, y de el liçençiado Polo e Rodrigo de Orellana, sus encomenderos, en el pleito que tratan con los caçiques de Paria sobre las tierras:

I. Primeramente sean preguntados si conoçen a los dichoz [sic] [tachado: "nos"; tachadura no reconocida al pie ni al final] don Hernando Cuyo y don Diego Tanquire e Don Gerónimo Cuyo, caçiques del valle de Cochabamba, y a el liçençiado Polo y a Rodrigo de Orellana, sus encomenderos, y si tienen notiçia de las tierras del asiento de Poto Poto y de la chácara llamada Illaurco y la chácara de Colchacollo y la chácara que llaman Anocaraire y la chácara que llaman Villaoma y las demás.

II. Iten, si saven, etçétera, que del dicho valle de Cochabamba son caçiques prinçipales dél don Gerónimo Cuyo y don Diego Tanquire y don Hernando Cuyo, caçiques de la encomienda de[1] liçençiado Polo y de Rodrigo de Orellana, y que todas las dichas chácarras [sic] de Poto Poto e Illaurco y de Colchacollo y de Anocaraire y de Villaoma y todas las demás, que coxen y siembran los indios mitimaes puestos por el Inga en el dicho valle de Cochabamba, son del dicho valle y están en los términos y distrito e tierra de los dichos caçiques. [351v]

III. Iten, si saven, etçétera, que al tiempo que el Inga señaló las dichas chácarras, las tomó y adjudicó para sí propio y para que, lo que dellas se coxiese, comiese él y su gente de guerra, llevándoselo a la çiudad del Cuzco en sus ganados, sin que las personas que venefiçiavan el dicho maíz se pudiesen aprovechar dello en ninguna manera, lo qual se hazía ansí en todas las chácaras que el Inga tenía propias suyas para el dicho efeto [sic].

IIII $^{\circ}$. Iten, si saven, etçétera, que, en las dichas chácarras que el Inga señaló para sí e tomó a los dichos indios de Cochabamba, puso en ellas mitimaes, para que las sembrasen, benefiçiasen y coxiesen, de la provinçia de Paria, ansí soras como uros, y de la provinçia de los quillacas y de la provinçia de los chichas y de la provinçia de los carangas y de la provinçia de Chile y de la provinçia de los chilques, que es junto al Cuzco, y de 
otras munchas [sic], para que entendiesen en el dicho benefiçio y coxiesen la comida para el dicho Inga. Digan lo que saven.

V. Iten, si saven, etçétera, que al tiempo que los españoles entraron en estos reinos y los pusieron debaxo del amparo y dominio de Su Magestad, los dichos indios mitimaes, que estavan en el dicho valle de Cochabamba para benefiçiar las dichas tierras y sementeras del Inga, fueron encomendados con sus chácarras [352] e tierras en Rodrigo de Orellana y en Juan de Caravajal [sic], a quien suçedió Camargo y últimamente el liçençiado Polo. Digan lo que saven.

VI. Iten, si saven, etçétera, que, por virtud de la dicha encomienda, todos los dichos mitimaes quedaron devajo de la subjeçión de los caçiques de Cochabamba, y antes de la tasa y después de la tassa [sic] contribuyen e pagan su tassa con los dichos caçiques y sienbran para su tributo las tierras que antes estavan señaladas por el Inga. Digan lo que saven.

VII. Iten, si saven, etçétera, que, devaxo de la encomienda del dicho Rodrigo de Orellana, están los indios mitimaes quillacas y los mitimaes carangas y los mitimaes chilques y chiles y collas y de Asángaro, los quales tienen pueblos en el dicho valle de Cochabamba y están en las mismas tierras que se venefiçiavan para el Inga y acuden con sus tributos al dicho don Hernando Cuyo e a Rodrigo de Orellana, su encomendero.

VIII ${ }^{\circ}$. Iten, si saven, etçétera, que los indios uros y soras mitimaes del repartimiento de Paria questavan en Hayata y al presente están, fuera de algunos que [352v] se an juntado, y los que estavan en Cota y en otros poblezuelos soras y uros, todos son y an sido $^{29}$ sujetos al caçique don Gerónimo Cuyo y don Diego Tanquire después de la dicha encomienda y siempre an tributado con ellos e ayudádoles a pagar su tassa a Juan de Caravajal y a Camargo y al liçençiado Polo, sus encomenderos. Digan lo que saven.

IX. Iten, si saven, etçétera, que los indios caracaras y chichas y charcas yamparayes questavan mitimaes en Cochabamba para el benefiçio de las dichas chácarras del Inga, todos ansimismo fueron encomendados al dicho Juan de Caravajal y sirvieron al dicho Alonso de Camargo y sirven y an servido al liçençiado Polo devaxo de la sujeçión del dicho don Gerónimo Cuyo e don Diego Tanquire, caçiques del dicho valle de Cochabamba, sin aver cosa en contrario.

$X$. Iten, si saven, etçétera, que, después de las dichas encomiendas, nunca los indios carangas carangas [redundancia en el original] ni quillacas ni chichas ni yamparayes, soras ni uros an enbiado a sembrar al dicho valle

29 Entendemos este pasaje como: “... que los indios uros y soras mitimaes del repartimiento de Paria questavan en Hayata (y al presente están, fuera de algunos que [352v] se an juntado [con ellos]) y los que estavan en Cota y en otros poblezuelos soras y uros, todos son y an sido ...". 
de Cochabamba ni tomado ni aprovechádose de las tierras quel dicho Inga señaló para sí, sino tan solamente los mitimaes questavan en el dicho valle, dándoles tributos [353] a los dichos caçiques y contribuyendo con ellos con su tassa. ${ }^{30}$

XI. Iten, si saven, etçétera, que dende tres o quatro años a esta parte, después que Juan Gonçales fue a visitar por comisión de Antonio de Hoznayo, estando el liçençiado Polo ausente en serviçio de Su Magestad por corregidor en la çiudad del Cuzco, algunos indios uros del repartimiento de Paria se a[n] entrado y hecho sus casas en el dicho pueblo de Hayata y enpeçado a sembrar algunas tierras. Digan lo que saben.

XII. Iten, si saven, etçétera, que, si algún indio uro de Paria, antes de la dicha visita, querían $[$ sic $]$ sembrar y sembravan en el dicho valle, pagava a los dichos indios de Cochabamba tributo y les ayudava con sus personas [sic]. Digan lo que saven.

XIII. Iten, si saven, etçétera, que el dicho liçençiado Polo tiene su chácarra y sementera en el asiento y chácarra de Poto Poto y la siembra y coxe de doze años a esta parte sin contradiçión de persona alguna; y un pedaço de la dicha chácarra siembran los caçiques de la dicha su encomienda y otros indios della para pagar su tasa. Digan lo que saven.

$\mathrm{XIIII}^{\circ}$. Iten si saven, etçétera, que, después que Su Magestad hizo el repartimiento en este reino, repartió ansimismo [353v] todos los mitimaes, tierras y chácarras en el mismo lugar donde los halló, y que las tierras que venefiçiavan se quedaron para los dichos indios y sus encomenderos, lo qual fue universal en todo este reino, y ansí los indios carangas se quedaron sin las tierras y mitimaes en la costa, y lo mismo los de Chucuito y todos los demás, los quales fueron repartidos a la çiudad de Arequipa, y después, si traen comida de los dichos valles de mitimaes, es comprándola por sus dineros y rescate. ${ }^{31}$ Digan lo que saven.

XV. Iten, si saven, etçétera, quel pueblo de Totora, que está junto a los Andes, está poblado de mitimaes charcas del valle de Cochabamba, questavan allí puestos para benefiçio de chácarras del Inga, que avía tomado para sí, e por virtud de la encomienda que se hizo por Su Magestad se encomendaron, con sus tierras y chácarras, a don Gómez de Lima y a Luis Perdomo, y agora los posee Antonio Alvarez y Su Magestad, sin que los indios de Cochabamba gozan [sic] dellos ni de las dichas chácarras, y ansí se haze en todos los demás deste reino donde acaeçió lo susodicho. Digan lo que saven.

30 Creemos que se debe leer: “... dándoles [estos mitimaes] tributos [353] a los dichos caçiques [don Gerónimo Cuyo y don Diego Tanquire] y contribuyendo con ellos con su tassa."

31 Creemos que se debe leer: “... y después, si traen comida [los carangas o los de Chucuito] de los dichos valles de mitimaes, es comprándola por sus dineros y rescate ...”. 
XVI. Iten, si saven, etçétera, que los indios soras de Paria tienen y poseen en su tierra munchas chácarras de maíz y todas las que el Inga tenía señaladas en ella, de donde an pagado y pagan sus tributos, en los valles de Çicaya, Capinota y Charamoco y Cuchira y otros munchos valles, donde cómodamente siembran y coxen para sus comidas y tributos. [354]

XVII. Iten, si saven, etçétera, quen todos estos reinos donde quiera que ay indios uros, nunca el Inga les repartió ni dio tierras de maíz para ellos mismos. Digan lo que saben.

XVIII ${ }^{\circ}$. Iten, si saven, etçétera, que al tiempo que el dicho Juan Gonçales visitó el dicho valle, tubo atado y mandado pringar $^{32}$ al caçique prinçipal del repartimiento del liçençiado Polo, que se llama don Gerónimo Cuyo, y a otros. Digan lo que saven.

XIX. Iten, si saven, etçétera, que todo lo susodicho es público y notorio.

El liçençiado Polo. El liçençiado Pedro de Herrera. Françisco Muñoz.

Tristán Sánchez [firmado y rubricado]

\section{INTERROGATORIO CONTRA LOS INDIOS DE TAPACARÍ}

[400] + Por las preguntas siguientes sean preguntados los testigos que fueren presentados por parte de don Françisco y don Gerónimo Cuyo y don Diego Tanquiri [sic], caçiques principales del dicho valle de Cochabanba [sic], y de sus encomenderos en el pleito que tratan con los caçiques e indios de Tapacarí sobre las tierras y suyos de Colchacollo, Poto Poto e Illaurco, que son en el dicho valle de Cochabanba:

1. Primeramente sean preguntados si conoçen a las partes y si saben las dichas tierras, suertes y suyos de Colchacollo, Poto Poto e Illaurco, y si tienen notiçia del dicho pleito.

2. Iten, si saven, etsétera, que [en] todo el dicho valle de Cochabanba no ay naturales, sino todos mitimaes de diferentes partes, las [sic] quales puso allí el Inga y partió y dividió las tierras del dicho valle por suios [sic]

32 Les mandó torturar de la siguiente manera, que describiría el español Pedro Sánchez, uno de los testigos: "mandó [...] Joan Gonçales atar al dicho don Gerónimo Cuyo con otros tres o quatro indios a unas estacas que mandó hincar en el suelo, y ansí tendidos en el suelo los pringó el dicho Joan Gonçales a todos con toçino ardiendo puesto en un asador, y en el toçino astillas de ganchos ardiendo; y ansí los pringó él propio y indios a quien lo mandava" (f. 392 en el mismo volumen, EC-16). 
y suertes, repartiéndolos a los dichos mitimaes según la cantidad de gente que cada uno $[\mathrm{sic}]^{33}$ tenía.

3. Iten, si saven, etsétera, que [entre renglones: "de"] cada una de las provinçias de quel Inga puso mitimaes en el dicho valle de Cochabanba, a quien repartió los dichos suios y suertes, residían en el dicho valle por mitimaes cantidad de indios, así como de Paria, Tapacarí, aullagas y quillacas, charcas y caracaras y [de] Chile,$^{34}$ los quales estavan y residían allí por mitimaes para efeto de senbrar y coger [en] las dichas tierras, suertes y suios que les estavan señalados.

4. Iten, si saven, etsétera, que con todo lo que de las dichas tierras se cogía acudían al Inga y a sus mayordomos y lo llevaban y ponían en los depósitos de Paria y Tapacarí, questavan fechos para el dicho efeto, de donde los ganados del Inga lo ponían en los depósitos de Luricachi, y de allí lo llevavan otros hasta el Cuzco, de manera que todo el maíz e comida que se cogía en los dichos suyos y suertes del valle de Cochabanba se ponía en el Cuzco por la horden susodicha, sin aprovecharse dello personas algunas en el camino [400v] ni gastarlo ni consumirlo hasta que llegava a la dicha çiudad. Digan lo que saven.

5. Iten, si saven, etsétera, que para efeto que no huviese descuido en lo susodicho y lo senbrasen y cogiesen a tiempo, y para que en lo que se cogía oviese recaudo y no se tomase ni hurtase cosa alguna dello, tenía el Inga puestos mayordomos ingas en el dicho valle, los quales tenían cuidado de lo susodicho y de castigar a quien hazía lo contrario, digan lo que saven, por tener como tenía aquel valle de Cochabanba por cosa propia suya.

6. Iten, si saven, etsétera, que para poner los dichos mitimaes en el dicho valle echó dél los naturales que le ponían $[\text { sic }]^{35}$ y hera suyo, que heran los indios cotas y chuis y de otras naçiones, de los quales no dexó ninguno en el dicho valle de Cochabanba. ${ }^{36}$

33 Entendemos que este "uno" puede referirse a cada uno de los caciques de los mitimaes, y más en concreto a cada uno de los tres caciques del pleito: "don Francisco, don Gerónimo Cuyo y don Diego Tanquiri". Una interpretación alternativa, apoyada por el contenido de la pregunta 3, es la de entender que "uno" se refiere a cada uno de los pueblos de donde el Inca mandó sacar los mitimaes. En el interrogatorio, sin embargo, aparecen dos vocablos femeninos para referirse a estos pueblos de origen: "partes" y "provinçias". En las declaraciones de los testigos aparecen dos términos femeninos más: "naçiones" y "generaçiones".

34 Sic en el original, que nosotros entendemos como: “... cantidad de indios, así de Paria como de Tapacarí, aullagas y quillacas, charcas y caracaras y [de] Chile ...”.

35 Entendemos que el verbo "poner" tiene aquí su acepción n. 28 de la 19. edición del Diccionario de la Lengua Española de la Real Academia, que es la que manejamos: "oponerse a uno; hacerle frente o reñir con él".

36 El expediente del pleito de los carangas contradice esta información, al señalar que el Inca dejó en el valle a una parte de los naturales. Después de la llegada de los españoles, se constituyó con ellos la encomienda de Sipe Sipe ("Proceso de los indios carangas...", f. 406). 
7. Iten, si saven, etsétera, que los dichos indios que [entre renglones: "de"] cada provinçia estava[n] allí puestos por mitimaes, y residían en el dicho valle de hordinario, ${ }^{37}$ éstos tan solamente senbra [tachado: "un"] van en él lo que se les repartía para su comida, limitadamente, sin llevar cosa alguna de lo demás, ni contribuir con ello a caçiques ni otra persona donde heran naturales, porque si otra cosa fuera, por ser horden universal, fuera muy notorio y los testigos lo supieran.

8. Iten, si saven, etsétera, que de la provinçia de Tapacarí residían en las dichas tierras de Colchacollo, Poto Poto e Illaurco treinta o quarenta indios mitimaes de hordimario [sic], que entendían en el benefiçio de los dichos suyos y suertes de tierra y senbraban allí para sus comidas tan solamente, de los quales hera caçique y mitima en el dicho valle de Cochabanba Pomacollo, natural de Tapacarí, el qual dejó un hijo que se llama don Luis Mamani, que [401] que [redundancia en el original] agora reside en Tapacarí. Digan lo que saven.

9. Iten, si saven, etsétera, que al tiempo que los españoles entraron en estos reinos, y en nonbre de Su Magestad los conquista[entre renglones: "ron"] [tachado: "doras"], poblaron y repartieron, todos los repartimientos donde heran los dichos mitimaes se encomendaron a diferentes personas, y fizieron encomienda aparte de cada una de las dichas provinçias, como de Paria, Tapacarí, Sipi Sipi [sic], chichas, carangas, aullagas y quillacas y los indios de Chile, de las quales partes y de otras muchas son los mitimaes. Digan lo que saven.

10. Iten, si saven, etsétera, que todos los mitimaes que residen en el dicho valle de Cochabanba por sí y aparte se encomendaron en Rodrigo de Orellana y Juan de Caravajal, en cuya parte suçedió Alonso de Camargo, y e [redundancia en el original] en esta misma el liçençiado Polo Ondegardo, vezino desta çiudad, ${ }^{38}$ con sus tierras e chácaras, como todas las demás encomiendas. Digan lo que saven.

11. Iten, si saven, etsétera, que los indios de Tapacarí [entre renglones: "y Paria"; no reconocido al pie ni al final], por estar çerca del dicho valle, alçaron y llevaron los dichos mitimaes a las dichas sus tierras y provinçias, por estar tan solamente siete leguas [tachado: "tan solamente"; había originalmente una redundancia] de Cochabanba, después de lo qual, y al tiempo que se hizo la visita por el presidente Gasca, los indios de Cochabanba fueron visitados y tasados con las tierras del dicho valle, y al respeto [sic] dellas les mandaron dar el tribu[entre renglones: "to"] dellas a sus encomenderos.

37 Por contraposición a los que estaban en el valle sólo temporalmente, que eran los mitayos.

38 La Plata (hoy Sucre), lugar donde el secretario de la Audiencia de Charcas, Tristán Sánchez, copió y firmó el interrogatorio. 
12. Iten, si saben [sic], etsétera, que por la dicha razón, con ser los indios de Tapacarí tantos y más que los de Cochabanba, los indios de Cochabanba fueron tasados en más de mil y seisçientas hanegas de maíz y más y allende que diesen tierras para sus encomenderos, de las quales, al respeto de la tasa, cogen y an cogido en cada un año más de dos mil anegas [sic] de trigo y maíz, y los indios de Tapacarí aún no fueron tasados en la mitad. Digan lo que saven.

13. Iten, si saven, etsétera, que después de la dicha visita y tasa, los [401v] dichos indios de Cochabanba an senbrado de hordinario las dichas chácaras de Poto Poto, Colchacollo e Illaurco, y dellas mismas an dado tierra al dicho liçençiado Polo e Rodrigo de Orellana, sus encomenderos, conforme a la tasa, en las quales an senbrado e cogido mucha cantidad de maíz y trigo en cada un año, y agora ansimismo las tienen senbradas. Digan lo que saven.

14. Iten, si saven, etsétera, que los dichos indios de Tapacarí tienen en su tierra dicha Itapaya y otros muchos valles donde cogen maíz para sus comidas, porque la mayor parte de su tierra es tenplada [sic] y donde se coge el dicho maíz en gran abundançia $[$ sic $] .{ }^{39}$ Digan lo que saven.

15. Iten, si saven, etsétera, que, si los dichos indios de Tapacarí cogen e sienbran en el dicho valle de Cochabanba, son tierras algunas que arriendan y pagan dellas lo que se conçiertan para algunos caçiques particulares $[\mathrm{sic}],{ }^{40}$ diferentes de las dichas chácaras y suertes de Poto Poto, Illaurco y Colchacollo, sobre ques este pleito.

16. Iten, si saven, etsétera, que todo lo susodicho es público e notorio e pública boz [sic] e fama.

El liçençiado Polo. Don Hernando. Don Gerónimo.

Tristán Sánchez [firmado y rubricado].

39 Itapaya está al suroeste del valle de Cochabamba y por tanto fuera de las chácaras de Poto Poto, Colchacollo e Illaurco. La pregunta del interrogatorio es poco clara. Entendemos que se alega que los indios de Tapacarí tienen ya suficientes tierras de maíz fuera del valle de Cochabamba como para pedir más en él. El testigo Juan Antón Charme, "indio sora prinçipal de Sipe Sipe”, contestó a la pregunta confirmando su contenido general, pero añadiendo una crítica precisión: que "las tierras de Itapaya, que son de los indios de Tapacarí, y otros valles que tienen, son tierras tenpladas y en ellas cogen maíz, aunque son tierras delgadas" (f. 405).

40 De nuevo el texto del interrogatorio es poco claro. Lamentablemente, Juan Antón Charme no supo contestar a esta pregunta. De hecho, solamente dos testigos de un total de siete supieron hacerlo. Felipe Aquise, "prinçipal de Sipe Sipe", respondió tan sólo "que lo en la pregunta contenido oyó desir [...] a indios de Tapacarí y a los de Cochabanba: que les arrendavan tierras para senbrar" (f. 408). Alonso Tiamire, "indio sora de Sipe Sipe”, contestó "que los indios de Tapacarí alquilan o arriendan tierras a los de Cochabanba en este [...] valle para senbrar" (f. 410v). Nadie dice quiénes eran los "caçiques particulares" ni a qué comunidad pertenecían. ¿Eran caciques de Tapacarí o de Cochabamba? Nosotros entendemos que la pregunta alega que los indios de Tapacarí habían llegado a un acuerdo (un "concierto" con los de Cochabamba para que, a cambio de una renta de arrendamiento, pudieran cultivar algunas tierras en el valle, cuyo producto era para "algunos caçiques particulares" de Tapacarí. 